\title{
Isokinetic Strength of the Dominant and Non-dominant Elbow in Elite Male Volleyball Players
}

\author{
Elif Cengizel $^{1}$ \\ ${ }^{1}$ Department of Trainer Education, Faculty of Sport Sciences, Gazi University, Ankara, Turkey \\ Correspondence: Elif Cengizel, Gazi University, Abant Sok. No: 12, Yenimahalle, 06330 Ankara, Turkey. \\ E-mail: elifoz@gazi.edu.tr
}

Received: September 16, 2019

Accepted: October 10, 2019 Online Published: October 24, 2019

doi:10.5539/jel.v8n6p65

URL: https://doi.org/10.5539/jel.v8n6p65

\begin{abstract}
The purpose of this research is to compare the elbow isokinetic strength applied at different angular velocities on the dominant and non-dominant side in elite male volleyball players. Fifteen elite volleyball players participated in the research. Isokinetic elbow flexion and extension strength were separately obtained on concentric/concentric dominant and non-dominant side as 5 repetitions at $60^{\circ} . \mathrm{s}^{-1}$ angular velocity, 10 repetitions at $180^{\circ} . \mathrm{s}^{-1}$ and 15 repetitions at $300^{\circ} . \mathrm{s}^{-1}$. In the research, the peak torque (PT), peak torque/body weight (PT/BW), flexion/extension ratio (B/T), angle of PT, work and power parameters were compared between the dominant and non-dominant elbows. No significant difference was found between the dominant and non-dominant side in the elbow isokinetic strength parameters of the subjects at three different velocities. A significant difference was found at three different velocities only in the angle of PT flexion $(p<0.05)$. It is thought that this difference may result from the muscle shortening that may occur on muscle length (longitudinal effect) as a result of the more concentric contraction of the muscle on the dominant side compared to the non-dominant muscle. Consequently, there is not any isokinetic strength difference between the dominant and non-dominant elbow in elite male volleyball players. Isokinetic elbow test can provide important information regarding the potential risk factors for elbow injuries. For this reason, it is recommended to include this test in the functional screening of volleyball players.
\end{abstract}

Keywords: isokinetic strength, volleyball, dominant, elbow, upper extremity

\section{Introduction}

Volleyball differs from other sports in terms of having very different, frequent and rapidly changing game situations (Öz, 2019). This game has been one of four popular international sports in males and females since the 1964 Olympic Games (Tilp, 2017).

In elite athletes, muscle strength and power are among the most important factors affecting success in a competition in addition to technical and tactical skills (Cardoso Marques, González-Badillo, \& Kluka, 2006; Marques, van den Tillaar, Vescovi, \& Gonzalez-Badillo, 2008). An elite spiker exhibits spike performance in a total of 16-20 hours of training per week and performs approximately 40000 spikes in a year (Kugler, Kruger-Franke, Reininger, Trouillier, \& Rosemeyer, 1996). Volleyball players should gain strength to apply technical elements successfully and increase muscle endurance to maintain throughout a competition (Cardoso Marques et al., 2006). Häkkinen (1993) noted that the magnitude of both strength and explosive power training stimuli should be carefully observed during the competition season to protect explosive power. Cardoso Marques et al. (2006) suggested that although volleyball is not a sports branch consisting of mere strength, athletes should perform maximal strength training at least for 8 weeks during the preparation process for the long-term season due to the need for the strength parameters.

Maximal isokinetic strengths of athletes should be monitored during a season. Following these evaluations, it is very important to determine the strengths and weaknesses of athletes and to prevent sports injuries that may occur during the season. In addition, strength trainings can be planned individually in line with the findings obtained from maximal isokinetic data. However, elbow isokinetic strengths of elite male volleyball players are still not very clear.

In many sports branch, athletes perform strength training and volleyball is one of these sports (Marques et al., 
2008). Spike is the most important technical component affecting the score in volleyball (Palao, Santos, \& Ureña, 2004). During a spike, the velocity in the hand is presented with a kinetic chain through the participation of hip, body, elbow and hand (Cisar \& Corbelli, 1989; Rokito, Jobe, Pink, Perry, \& Brault, 1998). This is associated with elbow and shoulder joint extension velocity (Ferris, Signorile, \& Caruso, 1995; Singh \& Rathore, 2013). Vint and Hinrichs (2004) determined in a 3D analysis of US national team female players that the spike velocity realized with $44.9 \%$ elbow and $30.5 \%$ shoulder joint velocity. The explosive power and pronation occurring in the forearm are like a "whip". This position extends the spike arm (lever arm) and thus maximizes the potential velocity of the hand (Cisar \& Corbelli, 1989). Forthomme, Croisier, Ciccarone, Crielaard, and Cloes (2005), proved that there was a significant relationship between the spike velocity and the strength of the internal rotators of the dominant shoulder and the strength of the flexors and extensors of the dominant elbow. Wagner et al. (2014) and Coleman, Benham and Northcott (1993) defined that high ball velocity is associated with maximal humeral velocity. The increase in the range of motion of the elbow joint is the main factor of the spike technique and varies between elite players and beginners. A coordinated muscle activity increases moment (Tilp, 2017).

Isokinetic tests are used to determine torque values in different ranges of motion at a constant velocity (Gallagher, Cuomo, Polonsky, Berliner, \& Zuckerman, 1997). Agonist and antagonist muscle imbalance and weakness are generally accepted as the sign of an injury. Muscle imbalance can be revealed as a result of isokinetic evaluations (Ruivo, Pezarat-Correia, \& Carita, 2012).

It was determined that the research conducted on isokinetic power in volleyball mostly focused on knee flexion and extension (Çelenk, Öz, Öner, \& Öz, 2019; Dervišević \& Hadžić, 2012; Hadzic, Sattler, Markovic, Veselko, \& Dervisevic, 2010; Magalhaes, Oliveira, Ascensao, \& Soares, 2004; Sattler, Sekulic, Esco, Mahmutovic, \& Hadzic, 2015; Schons et al., 2018). In terms of the upper extremity, isokinetic strength of the shoulder joint was mostly examined (Cingel et al., 2006; Hadzic, Sattler, Veselko, Markovic, \& Dervisevic, 2014; Stickley, Hetzler, Freemyer, \& Kimura, 2008; Wang \& Cochrane, 2001). The studies, whose number is limited, and which examine the elbow isokinetic strength, are on female volleyball players (Alfredson, Nordström, Pietilä, \& Lorentzon, 1998; Alfredson, Pietilä, \& Lorentzon, 1998). As mentioned above, considering the importance of the elbow joint in spike and serve which are the most commonly used technical motions in volleyball, it is very important to determine the elbow isokinetic strength and to investigate strength imbalance if any. According toAlfredson et al. (1998), spike and serve occur at high angular velocities in volleyball. Therefore, they reported that it would be more appropriate to measure muscle strength at high angular velocities like $60^{\circ} . \mathrm{s}^{-1}$ and $180^{\circ} . \mathrm{s}^{-1}$. However, I think that measurements should be taken also at the angular velocities like $300^{\circ} . \mathrm{s}^{-1}$ at which movements can be performed with more repetitions in terms of maintaining the current strength during the competition. Accordingly, the purpose of this research is to compare the elbow isokinetic strength applied at different angular velocities on the dominant and non-dominant side in elite male volleyball players.

\section{Method}

\subsection{Participants}

Fifteen healthy elite male volleyball players participated in the research voluntarily. All participants are super league players and 10 of them are national team players. Before starting the research, the subjects were informed regarding the study design and possible risks. The players, who had an upper extremity injury or surgery in the last six months, were not included in the research.

\subsection{Research Protocol}

Measurements were performed on the players who completed their one-month pre-season trainings before the competition period. The dominant arm (spiked hand) of all players is right. Before the measurement, the subjects completed warm-up with line drills and dynamic stretching for approximately 30 minutes.

The test protocol was performed on four separate days. One day rest was given between each measurement day. The body height, body weight, body mass index (BMI) and fat percentage of the players were determined on the first day. The isokinetic strength of the dominant and non-dominant elbows was obtained on three separate days at three different angular velocities.

The bilateral elbow isokinetic strengths of the subjects were measured at three different angular velocities in flexion and extension movements: $60^{\circ} . \mathrm{s}^{-1}, 5$ repetitions (low angular velocity), $180^{\circ} . \mathrm{s}^{-1}, 10$ repetitions (moderate angular velocity), $300^{\circ} . \mathrm{s}^{-1}, 15$ repetitions (high angular velocity). Elbow flexion and extension movements were performed in concentric-concentric mode. Elbow isokinetic strength was determined by using the IsoMed 2000 isokinetic dynamometer (D.\&R. Ferstl GmbH, Hemau, Germany). The subjects were asked to perform 3 submaximal and 1 maximal repetitions on the isokinetic dynamometer before starting the test. During the test, 
the participants were in a sitting position on the dynamometer and stabilized from their shoulders and hips to the dynamometer in accordance with the protocol. During the test, the subjects were encouraged verbally.

\subsection{Statistical Analysis}

The following parameters were included in the research for elbow isokinetic strength measurements: PT, PT/BW, $\mathrm{B} / \mathrm{T}$, angle of PT, work and power. The descriptive statistics were performed through Sigma Plot 11.0 software (Systat Software, Inc). Paired t-test (Wilcoxon) was used for the comparison of the isokinetic strength of the subjects on the dominant and non-dominant sides. The significance level was determined as $\mathrm{p}<0.05$.

\section{Results}

The mean height of the subjects participating in the research was determined as $194.2 \pm 6.2 \mathrm{~cm}$, mean body weight $89.7 \pm 8.0 \mathrm{~kg}$, mean BMI $23.8 \pm 1.7 \mathrm{~kg} \cdot \mathrm{m}^{-2}$ and mean fat percentages $9.3 \pm 4.4$ (Table 1).

Table 1. Characteristics of the subjects

\begin{tabular}{llll}
\hline & Mean \pm SD & Min & Max \\
\hline Age (year) & $24.7 \pm 4.8$ & 18 & 34 \\
Years of experience (year) & $13.2 \pm 5.1$ & 6 & 25 \\
Body height $(\mathrm{cm})$ & $194.2 \pm 6.2$ & 184.3 & 209.0 \\
Body weight $(\mathrm{kg})$ & $89.7 \pm 8.0$ & 80.3 & 109.5 \\
BMI $\left(\mathrm{kg} / \mathrm{m}^{2}\right)$ & $23.8 \pm 1.7$ & 20.7 & 27.7 \\
Fat percentage (\%) & $9.3 \pm 4.4$ & 3.2 & 16.0 \\
\hline
\end{tabular}

The players' PTs produced during the flexion at different angular velocities were determined to be lower than the PTs produced during the extension (Tables 2, 3, 4).

Table 2. Elbow isokinetic strengths of the subjects at $60^{\circ} . \mathrm{s}^{-1}$ angular velocity

\begin{tabular}{llll}
\hline & Dominant & Non-dominant & $\mathrm{p}$ \\
\hline PT flex $(\mathrm{Nm})$ & $25.0 \pm 8.0$ & $28.1 \pm 12.9$ & .519 \\
PT ex $(\mathrm{Nm})$ & $57.2 \pm 10.4$ & $52.7 \pm 10.0$ & .217 \\
PT/BW flex (Nm/kg) & $0.34 \pm 0.15$ & $0.35 \pm 0.11$ & 1.00 \\
PT/BW ex (Nm/kg) & $0.78 \pm 0.15$ & $0.75 \pm 0.15$ & .272 \\
Flex/Ex ratio (B/T) & $46.4 \pm 10.9$ & $47.5 \pm 9.4$ & .391 \\
Angle of PT flex (degree) & $76.6 \pm 19.9$ & $59.7 \pm 14.6$ & $.013^{*}$ \\
Angle of PT ex (degree) & $69.3 \pm 14.0$ & $64.5 \pm 11.4$ & .293 \\
Work flex (Joule) & $48.5 \pm 16.8$ & $48.5 \pm 12.7$ & .784 \\
Work ex (Joule) & $114.4 \pm 21.1$ & $109.9 \pm 20.9$ & .131 \\
Power flex (Watt) & $22.1 \pm 8.2$ & $22.1 \pm 5.9$ & .787 \\
Power ex (Watt) & $53.1 \pm 11.2$ & $50.3 \pm 9.8$ & .103 \\
\hline
\end{tabular}

Note. *: $\mathrm{p}<0.05$, PT flex: peak torque flexion, PT ex: peak torque extension, BW: Body weight, B: Biceps, T: Triceps.

The highest PT was obtained at $180^{\circ} . \mathrm{s}^{-1}$ angular velocity on both dominant and non-dominant elbow (PT flexion $49.2 \pm 20.1 \mathrm{Nm}$, PT extension $118.1 \pm 20.7 \mathrm{Nm}$ in dominant, PT flexion 50.4 $\pm 15.6 \mathrm{Nm}$, PT extension $115.1 \pm$ 18.5 Nm in non-dominant).

Table 3. Elbow isokinetic strengths of the subjects at $180^{\circ} . \mathrm{s}^{-1}$ angular velocity

\begin{tabular}{llll}
\hline & Dominant & Non-dominant & $\mathrm{p}$ \\
\hline PT flex (Nm) & $49.2 \pm 20.1$ & $50.4 \pm 15.6$ & .854 \\
PT ex (Nm) & $118.1 \pm 20.7$ & $115.1 \pm 18.5$ & .422 \\
PT/BW flex (Nm/kg) & $0.30 \pm 0.15$ & $0.27 \pm 0.11$ & .469 \\
PT/BW ex (Nm/kg) & $0.60 \pm 0.21$ & $0.62 \pm 0.14$ & 1.00 \\
Flex/Ex ratio (B/T) & $52.8 \pm 24.2$ & $45.9 \pm 11.6$ & .295 \\
Angle of PT flex (degree) & $73.5 \pm 25.1$ & $56.8 \pm 18.0$ & $.038^{*}$ \\
Angle of PT ex (degree) & $71.8 \pm 28.2$ & $63.3 \pm 17.7$ & .144 \\
Work flex (Joule) & $35.8 \pm 16.3$ & $37.0 \pm 12.9$ & .809 \\
Work ex (Joule) & $88.1 \pm 21.1$ & $89.0 \pm 17.9$ & .814 \\
Power flex (Watt) & $37.6 \pm 19.1$ & $40.1 \pm 15.4$ & .671 \\
Power ex (Watt) & $99.6 \pm 25.7$ & $99.2 \pm 20.3$ & .932 \\
\hline
\end{tabular}

Note. *: $\mathrm{p}<0.05$, PT flex: peak torque flexion, PT ex: peak torque extension, BW: Body weight, B: Biceps, T: Triceps. 
This is followed by the PT produced at $300^{\circ} . \mathrm{s}^{-1}$ (PT flexion $48.6 \pm 22.6 \mathrm{Nm}$, PT extension $116.6 \pm 40.8 \mathrm{Nm}$ in dominant, PT flexion $49.3 \pm 19.5 \mathrm{Nm}$, PT extension $116.6 \pm 25.9 \mathrm{Nm}$ in non-dominant) and $60^{\circ} . \mathrm{s}^{-1}$ (PT flexion $25.0 \pm 8.0 \mathrm{Nm}$, PT extension $57.2 \pm 10.4 \mathrm{Nm}$ in dominant, PT flexion $28.1 \pm 12.9 \mathrm{Nm}$, PT extension $52.7 \pm 10.0$ $\mathrm{Nm}$ in non-dominant) angular velocities, respectively.

Table 4. Elbow isokinetic strengths of the subjects at $300^{\circ} \cdot \mathrm{s}^{-1}$ angular velocity

\begin{tabular}{llll}
\hline & Dominant & Non-dominant & $\mathrm{p}$ \\
\hline PT flex $(\mathrm{Nm})$ & $48.6 \pm 22.6$ & $49.3 \pm 19.5$ & .542 \\
PT ex $(\mathrm{Nm})$ & $116.6 \pm 40.8$ & $116.6 \pm 25.9$ & .993 \\
PT/BW flex $(\mathrm{Nm} / \mathrm{kg})$ & $0.22 \pm 0.12$ & $0.17 \pm 0.11$ & .250 \\
PT/BW ex $(\mathrm{Nm} / \mathrm{kg})$ & $0.50 \pm 0.17$ & $0.51 \pm 0.12$ & .818 \\
Flex/Ex ratio (B/T) & $48.0 \pm 14.5$ & $44.5 \pm 12.6$ & .395 \\
Angle of PT flex (degree) & $77.7 \pm 27.6$ & $52.5 \pm 28.8$ & $.033^{*}$ \\
Angle of PT ex (degree) & $81.9 \pm 9.0$ & $82.3 \pm 6.9$ & .561 \\
Work flex (Joule) & $25.9 \pm 12.4$ & $25.6 \pm 10.8$ & .561 \\
Work ex (Joule) & $59.3 \pm 23.5$ & $60.0 \pm 16.7$ & .864 \\
Power flex (Watt) & $36.1 \pm 20.0$ & $37.1 \pm 17.3$ & .463 \\
Power ex (Watt) & $93.3 \pm 40.0$ & $94.7 \pm 27.9$ & .853 \\
\hline
\end{tabular}

Note. *: $\mathrm{p}<0.05$, PT flex: peak torque flexion, PT ex: peak torque extension, BW: Body weight, B: Biceps, T: Triceps.

The lowest elbow isokinetic PT is at $60^{\circ} . \mathrm{s}^{-1}$ angular velocity. In the isokinetic strength parameters of the subjects, only the angle of PT flexion was found to be significantly different at three different angular velocities (dominant vs. non-dominant) $(\mathrm{p}<0.05)$. On the other hand, the angle of PT extension was not found to be significantly different at three different angular velocities. In terms of all remaining variables, no significant difference was found between the dominant and non-dominant elbow.

\section{Discussion and Conclusion}

Elbow and shoulder strength are important for serve and spike performance (Lidor \& Ziv, 2010). An explosive extension occurs on the elbow joint during a spike (Cisar \& Corbelli, 1989). For this reason, it is suggested to protect elbow isokinetic muscle strength with regular trainings to prevent elbow joint injuries that can occur during spike and serve movements that require explosive strength and block movement requiring good stabilization in volleyball.

The spike velocity was determined positively and significantly associated with the arm extension torque at $270^{\circ} . \mathrm{s}^{-1}$ angular velocity in NCAA Division I female volleyball players $(\mathrm{r}=.64$, Ferris et al., 1995). Alfredson, Nordström, et al. (1998) measured the dominant and non-dominant elbow flexion and extension isokinetic strength in female volleyball players at $60^{\circ} . \mathrm{s}^{-1}$ and $180^{\circ} . \mathrm{s}^{-1}$ angular velocities. As a result of their research, they detected a significant difference between the dominant and non-dominant elbow isokinetic strength (except for $180^{\circ} . \mathrm{s}^{-1}$ elbow flexion). Alfredson, Pietilä, et al. (1998) determined that the PT of the shoulder and elbow rotator muscles in volleyball players was higher than the sedentary females. However, no significant difference was found between the two groups in terms of elbow flexion PT. The researchers stated that this may have resulted from the fact that elbow flexors are used to decelerate the arm after hitting the ball in the technical elements such as spike and serve in volleyball. From this point of view, it is possible to state that elbow extensors are more active than elbow flexors and affect performance more in volleyball technical elements. In this research, the elbow flexion isokinetic strength was found to be quantitatively lower than the elbow extension isokinetic strength at all angular velocities.

Gallagher, Cuomo, Polonsky, Berliner, and Zuckerman (1997) compared elbow isokinetic strength in sedentary males at different angular velocities on the dominant and non-dominant sides. In their research, the subjects were divided into two groups as 20-30 years of old and 50-60 years of old. Although there was a significant difference between the dominant and non-dominant side in elbow flexion in terms of the isokinetic parameters (PT, work, power) of the subjects, no difference was detected between the dominant and non-dominant sides in elbow extension. They found that the elbow flexion and extension PT at high velocity $\left(180^{\circ} . \mathrm{s}^{-1}\right)$ was significantly lower than the PT produced at low velocity $\left(90^{\circ} . \mathrm{s}^{-1}\right)$. I think that the differentiation of these findings from the findings of this research results from the volleyball player subject group who performed a sports-specific upper extremity movement for many years.

Wittstein, Queen, Abbey, and Moorman (2010) did not find a significant difference between the dominant and 
non-dominant sides in terms of the elbow flexion PT in healthy adult males. The elbow flexion PT at $60^{\circ} . \mathrm{s}^{-1}$ angular velocity shows similarity with current research (dominant side $55.4 \pm 9.7 \mathrm{Nm}$, non-dominant side $52.0 \pm$ 7.6 Nm). However, the elbow flexion strength at $180^{\circ} . \mathrm{s}^{-1}$ angular velocity was very lower than the values that I obtained in this research (dominant side $86.1 \pm 7.7 \mathrm{Nm}$, non-dominant side $85.9 \pm 8.6 \mathrm{Nm}$ ). I think that this difference results from the fact that the participants in this research are athletes.

Forthomme et al. (2005) found that the spike velocity in male volleyball players was significantly correlated with the strength of dominant elbow flexors and extensors (concentric mode). They determined the mean concentric PT of the subjects as $60^{\circ} . \mathrm{s}^{-1}$ elbow flexion $60.6 \pm 8.6 \mathrm{Nm}$, elbow extension $68.5 \pm 15.9 \mathrm{Nm}, 180^{\circ} . \mathrm{s}^{-1}$ elbow flexion $47.9 \pm 8.3 \mathrm{Nm}$, elbow extension $55.4 \pm 9.3 \mathrm{Nm}$. They detected the B/T ratio as $0.91 \pm 0.14,180^{\circ} . \mathrm{s}^{-1} 0.87$ \pm 0.1 at $60^{\circ} . \mathrm{s}^{-1}$ angular velocity. They obtained the highest PT at low angular velocity. This finding conflicts with current study findings. I think that the strength produced at high angular velocities is more similar to the range of motion of spike, which is the most repetitive technical element in volleyball, compared to the strength produced at low velocities. In current study findings, the highest PT was obtained in dominant and non-dominant flexion and extension at $180^{\circ} . \mathrm{s}^{-1}$ and $300^{\circ} . \mathrm{s}^{-1}$ angular velocities. In addition, the $180^{\circ} . \mathrm{s}^{-1}$ elbow extension isokinetic strength (the agonist muscle of this motion is triceps) that I obtained in this research is almost two times more than the value obtained in Forthomme et al. research (while the $180^{\circ} . \mathrm{s}^{-1}$ elbow extension PT is $118.1 \pm 20.7 \mathrm{Nm}$ in current research, it is $55.4 \pm 9.3 \mathrm{Nm}$ in the study of Forthomme et al. (2005)). When the year of the research is taken into consideration, the differences in the findings obtained can be clarified when the changing game velocity and requirements are considered.

Following the literature review, it was determined that the elbow joint isokinetic strength was investigated in volleyball players in a limited number of studies. It is obvious that the focus is mostly on the isokinetic strength of the shoulder. Therefore, I think that this research will bridge an important gap in the literature. The fact that the years of the researches conducted are also out of date makes our study attention-grabbing. Moreover, the fact that the subject group consists of national and super league players is one of the strengths of this current research. However, the limited number of the sample group is one of the limitations of this research. Consequently, there is not any isokinetic strength difference between the dominant and non-dominant elbow in elite male volleyball players. The lowest elbow isokinetic strength (flexion \& extension) was obtained at low angular velocity $\left(60^{\circ} . \mathrm{s}^{-1}\right)$. The elbow extensor muscle strength was higher than the elbow flexor muscle strength on the dominant and non-dominant side. These findings can also be used as a reference by volleyball team coaches, trainers and conditioners. Due to the need for strength in volleyball, it is important to measure and follow the strength measurements of the players throughout the season. However, strength imbalance can cause sports injuries. In order to determine this, it is suggested to evaluate the dominant \& non-dominant or agonist-antagonist strength of players.

\section{Acknowledgments}

The author Elif Cengizel thanks all the participants for allowing this research to take place. The author also expresses her sincere gratitude to Dr. Mehmet Günay \& Dr. Serdar Uslu for their time and to Elvan Sağlam \& Çağdaş Özgür Cengizel for effort throughout the measurements.

\section{References}

Alfredson, H., Nordström, P., Pietilä, T., \& Lorentzon, R. (1998). Long-term loading and regional bone mass of the arm in female volleyball players. Calcified Tissue International, 62(4), 303-308. https://doi.org/10.1007/s002239900436

Alfredson, H., Pietilä, T., \& Lorentzon, R. (1998). Concentric and eccentric shoulder and elbow muscle strength in female volleyball players and non-active females. Scandinavian Journal of Medicine \& Science in Sports, 8(5), 265-270. https://doi.org/10.1111/j.1600-0838.1998.tb00481.x

Cardoso Marques, M. A., González-Badillo, J. J., \& Kluka, D. A. (2006). In-season resistance training for professional male volleyball players. Strength and Conditioning Journal, 28(6), 16-27. https://doi.org/10.1519/00126548-200612000-00002

Çelenk, B., Öz, E., Öner, A. G., \& Öz, E. (2019). The relationship between isokinetic knee strength and jumping in young male volleyball players. Turkish Journal of Sport and Exercise, 21(1), 12-15. https://doi.org/10.15314/tsed.521569

Cingel, R. V., Kleinrensink, G., Stoeckart, R., Aufdemkampe, G., Bie, R. D., \& Kuipers, H. (2006). Strength values of shoulder internal and external rotators in elite volleyball players. Journal of Sports and Rehabilitation, 15, 237-245. https://doi.org/10.1123/jsr.15.3.236 
Cisar, C. J., \& Corbelli, J. (1989). The volleyball spike: A kinesiological and physiological analysis with recommendations for skill development and conditioning programs. NSCA Journal, 11(1), 4-9. https://doi.org/10.1519/0744-0049(1989)011<0004:TVSAKA >2.3.CO;2

Coleman, S. G. S., Benham, A. S., \& Northcott, S. R. (1993). A three - dimensional cinematographical analysis of the volleyball spike. Journal of Sports Sciences, 11(4), 295-302. https://doi.org/10.1080/02640419308729999

Dervišević, E., \& Hadžić, V. (2012). Quadriceps and hamstrings strength in team sports: Basketball, football and volleyball. Isokinetics and Exercise Science, 20(4), 293-300. https://doi.org/10.3233/IES-2012-00483

Ferris, D. P., Signorile, J. F., \& Caruso, J. F. (1995). The relationship between physical and physiological variables and volleyball spiking velocity. Journal of Strength and Conditioning Research, 9(1), 32-36. https://doi.org/10.1519/00124278-199502000-00007

Forthomme, B., Croisier, J.-L., Ciccarone, G., Crielaard, J.-M., \& Cloes, M. (2005). Factors correlated with volleyball spike velocity. The American Journal of Sports Medicine, 33(10), 1513-1519. https://doi.org/10.1177/0363546505274935

Gallagher, M. A., Cuomo, F., Polonsky, L., Berliner, K., \& Zuckerman, J. D. (1997). Effects of age, testing speed, and arm dominance on isokinetic strength of the elbow. Journal of Shoulder and Elbow Surgery, 6(4), 340346. https://doi.org/10.1016/S1058-2746(97)90001-X

Hadzic, V., Sattler, T., Markovic, G., Veselko, M., \& Dervisevic, E. (2010). The isokinetic strength profile of quadriceps and hamstrings in elite volleyball players. Isokinetics and Exercise Science, 18(1), 31-37. https://doi.org/10.3233/IES-2010-0365

Hadzic, V., Sattler, T., Veselko, M., Markovic, G., \& Dervisevic, E. (2014). Strength asymmetry of the shoulders in elite volleyball players. Journal of Athletic Training, 49(3), 338-344. https://doi.org/10.4085/1062-6050-49.2.05

Häkkinen, K. (1993). Changes in physical fitness profile in female volleyball players during the competitive season. The Journal of Sports Medicine and Physical Fitness, 33(3), 223-232.

Kugler, A., Kruger-Franke, M., Reininger, S., Trouillier, H. H., \& Rosemeyer, B. (1996). Muscular imbalance and shoulder pain in volleyball attackers. British Journal of Sports Medicine, 30(3), 256-259. https://doi.org/10.1136/bjsm.30.3.256

Lidor, R., \& Ziv, G. (2010). Physical and physiological attributes of female volleyball players-A review. Journal of Strength and Conditioning Research, 24(7), 1963-1973. https://doi.org/10.1519/JSC.0b013e3181ddf835

Magalhaes, J., Oliveira, J., Ascensao, A., \& Soares, J. (2004). Concentric quadriceps and hamstrings isokinetic strength in volleyball and soccer players. Journal of Sports Medicine and Physical Fitness, 44(2), 119-125.

Marques, M. C., van den Tillaar, R., Vescovi, J. D., \& Gonzalez-Badillo, J.-J. (2008). Changes in strength and power performance in elite senior female professional volleyball players during the in-season: A case study. Journal of Strength and Conditioning Research, 22(4), 1147-1155. https://doi.org/10.1519/JSC.0b013e31816a42d0

Öz, E. (2019). Voleybolda smaç tekniğinin vuruş yönlerine göre kinematik analizi. Ankara, Turkey: Gazi Kitabevi.

Palao, J. M., Santos, J. A., \& Ureña, A. (2004). Effect of team level on skill performance in volleyball. International Journal of Performance Analysis in Sport, 4(2), 50-60. https://doi.org/10.1080/24748668.2004.11868304

Rokito, A. S., Jobe, F. W., Pink, M. M., Perry, J., \& Brault, J. (1998). Electromyographic analysis of shoulder function during the volleyball serve and spike. Journal of Shoulder and Elbow Surgery, 7(3), 256-263. https://doi.org/10.1016/S1058-2746(98)90054-4

Ruivo, R., Pezarat-Correia, P., \& Carita, A. I. (2012). Elbow and shoulder muscles strength profile in judo athletes. Isokinetics and Exercise Science, 20(1), 41-45. https://doi.org/10.3233/IES-2012-0439

Sattler, T., Sekulic, D., Esco, M. R., Mahmutovic, I., \& Hadzic, V. (2015). Analysis of the association between isokinetic knee strength with offensive and defensive jumping capacity in high-level female volleyball athletes. Journal of Science and Medicine in Sport, 18(5), 613-618. https://doi.org/10.1016/j.jsams.2014.08.002 
Schons, P., Da Rosa, R. G., Fischer, G., Berriel, G. P., Fritsch, C. G., Nakamura, F. Y., ... Peyré-Tartaruga, L. A. (2018). The relationship between strength asymmetries and jumping performance in professional volleyball players. Sports Biomechanics, 3141, 1-12. https://doi.org/10.1080/14763141.2018.1435712

Singh, A. B., \& Rathore, V. S. (2013). Kinematic factors of off-speed and power spike techniques in volleyball. Journal of Education and Practice, 4(7), 112-118.

Stickley, C. D., Hetzler, R. K., Freemyer, B. G., \& Kimura, I. F. (2008). Isokinetic peak torque ratios and shoulder injury history in adolescent female volleyball athletes. Journal of Athletic Training, 43(6), 571577. https://doi.org/10.4085/1062-6050-43.6.571

Tilp, M. (2017). Volleyball: Handbook of sports medicine and science (2nd ed.; J. C. Reeser \& R. Bahr, eds.). Oxford, UK: Wiley and Blackwell.

Vint, P. F., \& Hinrichs, R. N. (2004). Factors related to the development of ball speed and to the incidence of one-legged landings in the front-row volleyball attack. Proceedings of the XXII Symposium of the International Society of Biomechanics in Sport, 135-138. Ottawa: ISBS.

Wagner, H., Pfusterschmied, J., Tilp, M., Landlinger, J., von Duvillard, S. P., \& Müller, E. (2014). Upper-body kinematics in team-handball throw, tennis serve, and volleyball spike. Scandinavian Journal of Medicine \& Science in Sports, 24(2), 345-354. https://doi.org/10.1111/j.1600-0838.2012.01503.x

Wang, H. K., \& Cochrane, T. (2001). Mobility impairment, muscle imbalance, muscle weakness, scapular asymmetry and shoulder injury in elite volleyball athletes. Journal of Sports Medicine and Physical Fitness, 41(3), 403-410.

Wittstein, J., Queen, R., Abbey, A., \& Moorman, C. T. (2010). Isokinetic testing of biceps strength and endurance in dominant versus nondominant upper extremities. Journal of Shoulder and Elbow Surgery, 19(6), 874877. https://doi.org/10.1016/j.jse.2010.01.018

\section{Copyrights}

Copyright for this article is retained by the author, with first publication rights granted to the journal.

This is an open-access article distributed under the terms and conditions of the Creative Commons Attribution license (http://creativecommons.org/licenses/by/4.0/). 